DOI: $10.35355 / 0000042$

\title{
TEMPOS, MUNDOS E HISTÓRIAS MADIJA
}

\author{
Wladimyr Sena Araújo* \\ Universidade Federal do Estado do Rio de Janeiro - UNIRIO \\ senawladimyr@gmail.com
}

\begin{abstract}
RESUMO: Este artigo tem como finalidade mostrar como os Madija, povo indígena da família Arauá (habitantes do sul do Amazonas, região central do Acre e, também, do Peru), concebem os tempos através de suas histórias, articulando-as com suas visões de mundos. Para isso, toma como exemplo o sistema dsoppineje como confluência de tempos, mundos e histórias. O dsoppineje é o sistema de saúde desse povo e o motivo central de sua existência. Os Madija vivem em constante conflito com a doença e buscam, frequentemente, a saúde. Esta relação é mítica e se materializa no cotidiano das aldeias por meio de enfermidades, geralmente causada por seres a mando de terceiros. Neste contexto, o xamã (também chamado de dsoppineje) desempenha o papel de buscar o reestabelecimento daqueles que estão em desequilíbrio físico e espiritual.
\end{abstract}

PALAVRAS-CHAVE: Cosmologia - História - Madija

\section{TIMES, WORLDS AND MADIJA'S HISTORY}

\begin{abstract}
This article aims to show how the Madija indigenous people of the Arauá Family (inhabitants of the South of Amazonas, central region of Acre and also in Peru), conceive the times through their stories, articulating them with their world visions. For this, is taken as an example the dsoppineje system as a confluence of times, worlds and stories. The dsoppineje is the health system of this people and the central reason for its existence. The Madija live in constant conflict with the disease and constantly seek health. This relationship is mythical and materializes in the daily life of the villages through illnesses, usually caused by beings at the behest of others. In this context, the shaman (also called dsoppineje) has the role of seeking to reestablish those who are physically and spiritually unbalanced.
\end{abstract}

KEYWORDS: Cosmology - History - Madija

\section{INTRODUÇÃO}

Doutorando em História pela Universidade Federal do Estado do Rio de Janeiro (UNIRIO). Mestre em Antropologia Social pela Universidade Estadual de Campinas (UNICAMP). 
Os Madija, habitantes do Peru e da região central do Acre e sul do Amazonas, no Brasil, fazem parte da família linguística Arawan, que inclui línguas como Arawá, Paumari e Yamamadi, pertencentes ao tronco linguístico Aruaque (TASTEVIN, 19081914). Perpassando os séculos XVIII a XX, esse povo recebeu diferentes terminologias - como Kulina, Curina, Corina e Tucurina - que lhe foram atribuídas por viajantes, missionários e exploradores (FUNAI, 1985).

O termo Madija significa "gente" e suas nominações remetem a diversos tipos de animais e vegetais que para a etnia constitui parte das gentes primordiais. Neste ponto, convém esclarecer que parcela expressiva desses indígenas recebe designações de animais, sendo caracterizados muito mais como caçadores do que com os povos agricultores. Não obstante, são encontradas identificações de determinados grupos com as plantas. Dessa forma, há dsomahi madija (gente da onça), pissi madija (gente do macaco-de-cheiro), acomi madija (gente da piranha), aboro madija (gente do papagaio), ccorobo madija (gente do peixe jeju), dsohuiji madija (gente do macaco-prego), nara madija (gente do jaci), tocodso madija (gente do jacaré-preto), aba madija (gente do peixe), jomo madija (gente do macaco-preto) e outros tipos de gentes. ${ }^{1}$ Todas as gentes Madija estão diretamente vinculadas às histórias antigas, quando os ancestrais primordiais desse povo se metamorfoseavam, de forma especial, em animais.

Os estudos e documentos consultados indicaram que esse povo foi mencionado durante o período de busca pelas "drogas do sertão", época na qual eram coletados e levados para a Europa diversos produtos extraídos da flora e fauna amazônica, como óleo de tartaruga, salsaparrilha, cacau, óleo de copaíba, dentre outros. Nesse contexto, da região do Juruá eram extraídos cacau, breu, copaíba, anil e óleos (BALESTRA, 2013). Os relatos produzidos por viajantes e missionários citaram os Madija como um dentre 49 povos catalogados no ano de 1709 na Amazônia. ${ }^{2}$

De acordo com relatórios produzidos por Francis de Castelnau, no atual território do Acre foram localizados na região do Juruá, descendo para o rio Tarauacá,

1 O pesquisador esteve em algumas ocasiões na Terra Indígena Kulina do Rio Envira entre os anos de 1990 e 2012. Entre 2010 e 2012, foi contabilizada a existência de 11 tipos de gente. Todavia, vários indígenas relataram que em tempos pretéritos o número era maior, reduzindo-se após a chegada das frentes de contato a partir do início do século XX, dada a grande quantidade de mortes ocasionada pela violência dos cariús (aqueles que não são índios) e pela introdução de doenças.

2 Este é o posicionamento de Onofre de Andrade e Bellarmino de Mendonça que se escoraram na versão de Sant'Anna Nery, autor de Le pays des Amazonas. Nesse contexto, é possível identificar termos como Colinas, Curina, Curiná, dentre outros (FUNAI, 1985). 
rumo ao Gregório e o Acuraua (CERQUEIRA, 2015). ${ }^{3}$ Ele os observou tanto no Xeruã, afluente da margem direita do rio Juruá, como no rio Tarauacá, quando coletavam ovos de tracajá durante o verão. ${ }^{4}$ Citou, ainda, outros grupos localizados a sudoeste, possivelmente nos rios Gregório e Acuraua, tributários do Tarauacá (FUNAI, 1985). Os grupos foram reputados como guerreiros que eram temidos pelos "brancos" e outros povos indígenas. ${ }^{5}$

$\mathrm{Na}$ expedição que realizou à Amazônia entre os anos de 1849 e 1858, o naturalista Henry Bates percebeu grupos com nome de Kulina em regiões do Amazonas, diferenciando-os daqueles observados na região do Alto Juruá/Tarauacá e do Alto Rio Purus. ${ }^{6}$ Eles foram, igualmente, localizados em outro ponto: a região do rio Envira.

O geógrafo William Chandless os mencionou na viagem exploratória ao rio Juruá no ano de 1867. Durante suas incursões no território, referenciou-se aos Culino situados entre a margem direita do Juruá e do interior deste rio até a boca do Xiruã em direção ao Tarauacá (CERQUEIRA, 2015).

No ano de 1905, Gregório Taumaturgo de Azevedo, prefeito do Alto Juruá, enviou relatório ao ministro do Interior do Brasil informando a existência de aldeias Kurina nas margens direita e esquerda do Alto Embira, além dos rios Muru, Acuraua e Paraná do Ouro (FUNAI, 1985).

Durante sua missão religiosa na Amazônia, o padre Constantin Tastevin (1928) manteve contatos com diversos agrupamentos indígenas no final do século XIX. Ele descreveu grupos às margens do rio Muru, afluente do Tarauacá ${ }^{7}$, um dos tributários da margem direita do rio Juruá. De acordo com o sacerdote, esses índios eram donos incontestes da margem esquerda do Muru, fazendo-se presentes também na margem direita do Alto Tarauacá (BALESTRA, 2013).

3 Cerqueira (2015) comenta que Castelnau realizou uma viagem entre os anos de 1843 e 1853 ao rio Juruá e identificou, por meio de informantes, um grupo de índios chamados de Culinos.

4 Sublinha-se que o verão amazônico se caracteriza como período de quase ausência de chuvas, um contraste com o "inverno", quando as chuvas chegam à região com maior intensidade.

5 Em seus relatos produzidos entre os anos de 1908 e 1914, Constantin Tastevin comentou a expulsão de "brancos" em 1885 no rio Gregório, afluente do Tarauacá (TASTEVIN, 1908-1914).

6 A viagem de Henry Bates se deu em parceria com Alfred Russel Wallace. Eles saíram de Liverpool no ano de 1848 e chegaram à foz do Amazonas após um mês de viagem. Todavia, como tinham interesses distintos resolveram se separar (ARAÚJO, 2018).

7 O rio Tarauacá recebe como afluentes importantes os rios Acuraua, Jurupari e Envira, sendo este último o local de morada para grupos Madija na atualidade. 
No ano de 1910 foi criado o Serviço de Proteção ao Índio e Localização de Trabalhadores Nacionais (SPILTN) vinculado ao Ministério da Agricultura. O órgão foi implantado durante a gestão de Nilo Peçanha, presidente da República, com o objetivo de prestar assistência aos indígenas e impor uma política voltada à aculturação, integração e assimilação. Sob este prisma, o SPILTN propiciou o desenvolvimento de uma postura paternalista e intervencionista do Estado em relação aos índios, que se tornaram dependentes da tutela estatal, devendo se submeter a um processo de transição em direção a uma sociedade não indígena (ALMEIDA, 2010).

Uma das estratégias definidas pelo SPILTN para alcançar esse objetivo consistia em integrar as comunidades às atividades rurais. No período em que prevaleceu tal concepção, o governo acreditava que a melhor forma de proporcionar cidadania aos índios seria sua transformação em trabalhadores rurais. Seguindo essa lógica, prefeituras e seringalistas do Acre passaram a assumir essa política do governo federal desde o início do século XX. No ano de 1913, por exemplo, prefeitos do Território Federal do Acre e proprietários de seringais centraram esforços para introduzir os indígenas como mão de obra destinada à prática do extrativismo, dado o declínio da atividade gumífera. De modo análogo, insistiam na incorporação dos índios às atividades agrícolas para que pudessem reforçar o suprimento alimentar de algumas sedes municipais.

Os séculos XIX e XX inscreveram na história dos Madija, e de outros povos indígenas da Amazônia, um capítulo bastante tenso, violento, brutal e impiedoso marcado pela chegada das frentes de colonização do sul e sudeste amazônico para a coleta do látex. Essa situação não passou despercebida aos viajantes e missionários, que a condenaram. A título de ilustração, cite-se Constantin Tastevin que, ao discorrer sobre a localização dos Madija nos rios Acuraua e Tarauacá, denunciou a forma pela qual um de seus grupos era tratado pelo explorador Ângelo Ferreira, que se utilizava de chicotes para submetê-lo ao trabalho compulsório na extração do caucho com vistas a produzir excedente comercializável (FUNAI, 1985). Tal exemplo demonstra que o contato das frentes de colonização com os indígenas para atender ao mercado externo ${ }^{8}$ resultou em um dos maiores genocídios conhecidos na história do continente americano.

8 Com a descoberta do processo de vulcanização por Thomas Hancock, na Inglaterra, e por Charles Goodyear, nos Estados Unidos, em 1844, John Boyd Dunlop criou os pneumáticos que inicialmente substituíram as rodas de ferro das carruagens. Posteriormente, a borracha foi utilizada para confecção de pneumáticos de automóveis e bicicletas. Nesse contexto, o látex se tornou matéria-prima 
Vinculado à essa realidade, os índios foram inicialmente empregados como mão de obra na extração do látex. No entanto, com o fracasso das experiências pioneiras os seringalistas começaram a considerá-los como obstáculo à instalação dos seringais na região. Dessa maneira, os proprietários de seringais estimularam grupos de seringueiros a participar de expedições com a finalidade de "limpar as áreas", matando muitos indígenas. Sob este prisma, os seringalistas patrocinaram "correrias", como eram chamadas as expedições com características de punição, extermínio ou apresamento. Os sobreviventes destes massacres eram capturados e "amansados" para que trabalhassem nos seringais como extratores de látex ou desempenhassem funções de caçador, canoeiro, pescador $^{9}$ e toqueiro ${ }^{10}$.

Cumpre destacar que são divisados dois tipos de "correrias" na região: o primeiro tinha o propósito nítido de extermínio, enquanto o segundo foi direcionado à "pacificação" ou "amansamento" dos indígenas com vistas à sua inserção no mercado de trabalho (IGLÉSIAS, 2008). Os estudos acerca da temática apontam que além do Brasil as "correrias" foram efetuadas no Peru. Neste país eram chamadas de "reduciones"11 que, para Michael Taussig (1993), constituíam formas escamoteadas de submeter o indígena a formas de trabalho impostas pelo sistema capitalista.

Esclareça-se que com o "amansamento", os índios, que anteriormente habitavam o centro da mata, passaram a fixar moradia nas margens dos rios. Em consonância, a passagem do centro à margem dos cursos d'água foi marcada pelo deslocamento, fragmentação espacial e mudanças na cultura e organização social. Neste sentido, os Madija tiveram que se adaptar a uma nova forma de vida vinculada ao trabalho para os patrões seringalistas (ALTMANN, 1994). Em situação debilitada, foram usados como mateiros para localizar áreas, fornecer produtos da mata (como caça, pesca e frutos) até acabarem se transmutando em seringueiros.

fundamental para a feitura de uma diversidade de produtos na Europa e nos Estados Unidos, produto indispensável para as indústrias (ARAÚJO, 2000).

9 O pescador tinha a seu encargo a tarefa de abastecer os seringais de proteína animal e que era fornecida principalmente para os seringalistas e alguns empregados (como gerentes, guarda-livros e caixeiros).

10 Os toqueiros eram subordinados ao mateiro, trabalhador responsável pelo reconhecimento das árvores de látex e sua demarcação. O desmate, delineamento das estradas de seringa e sua manutenção eram atribuições dos toqueiros.

11 De acordo com Taussig (1993), no Peru "reducir" ou "rescatar" constituíam termos sinônimos de "correrias", sendo correlatos à palavra inglesa conquista. 
Com a crise da produção extrativista provocada pela concorrência asiática, muitos seringais foram desestruturados, quadro que estimulou a intensificação do emprego da mão de obra indígena (VIVEIROS DE CASTRO, 1978). Os dados levantados na literatura esclarecem que no transcurso da década de 1970 os Madija ainda trabalhavam na Fazenda Califórnia localizada no Alto Rio Envira (ARAÚJO, 2012).

Acrescente-se a essas considerações que o avanço da frente extrativista resultou em outros problemas aos grupos indígenas da região, como doenças contraídas com o contato com os cariús, dependência de mercadorias e mudanças na organização social interna, o que desestruturou o modo tradicional de vida, além de impactar demograficamente essas populações.

O contato com os cariús constitui, na visão desse povo, tão-somente uma das narrativas possíveis da história dos Madija, visto que desenvolveram uma concepção particular para tratar o tempo. Neste sentido, a proposta deste artigo é de mostrar como eles compreendem o tempo e como esta convenção está umbilicalmente associada às suas narrativas (histórias) e mundos. Nessa lógica de raciocínio, toma-se o sistema dsoppineje como exemplo de conexão desses três elementos.

\section{OS MUNDOS}

Para entender os aspectos que doravante são apresentados, é importante atentar que para os Madija o mundo no qual vivem está em conexão direta a vários outros. Eles são chamados de nami budi, memé tsueni, memé etseni, patsô dsamarini, nami budi inamini-ka e hua hohopadé-dsa.

Isso posto, nessa concepção particular o mundo no qual se vive é chamado de nami. É onde se nasce, cresce e morre. Ele é composto por plantas, animais, vegetais, rios, floresta e uma série de outros elementos distribuídos por múltiplos lugares.

O mundo superior ao nami, ou acima das nuvens, é titulado como patsô dsamarini. Ele é um lugar formado, em sua maior parte, por água. É o local no qual se origina a chuva que banha o plano no qual se vive. Na sequência se encontra o memé tsuení (céu azul-escuro) e, mais abaixo, o memé etsení que, em oposição ao memé tsuení, é bastante claro e com ventos fortes. É no memé tsuení que estão os mesué codé, do que constituem exemplos o urubu e o jaburu, além de outros pássaros de carne tida 
Disponível em: www.revistafenix.pro.br

como ruim. No topo dos mundos se situa o patsô dsamariní ou memé huaji, lugar de residência dos heróis mitológicos da criação e do Maji que, para os moradores do Igarapé do Anjo, está relacionado ao sol. É um ser que tem as cores do arco-íris. Também é a morada do Ttottorodé, espécie de anta que produz o relâmpago ao pingar sua gordura sobre uma fogueira.

$\mathrm{Na}$ parte inferior ao nami se encontra o namibudi, ou interior do chão. Acreditam que os acontecimentos que transcorrem no nami também se desenrolam no namibudi. Observe-se, pois, que todos os elementos do namibudi são duplos do nami. É nele que se encontram os espíritos chamados de ikorime. É o mundo no qual habitam almas dos diversos tipos de bani (animais), como tatu, arara, porco-do-mato, veado, capivara, paca, anta, macaco, dentre outros. Lá também vivem os espíritos das pessoas que levam vida idêntica ao plano no qual se vive. Por fim, mais abaixo aparecem o namibudi inami-ká, que é escuro e desabitado, e o hua-hohopadé dsa, uma região seca e desértica na qual nunca há noite e que constitui a morada dos espíritos ruins (VIVEIROS DE CASTRO, 1978).

Percebe-se, assim, que os mundos apresentam diversas propriedades e representações. Se no memé huaji vivem Quira e Tamaco, aqueles que criaram o mundo e outras entidades tidas e havidas como boas, inversamente no último mundo abaixo do nami vagam os espíritos ruins ligados ao desequilíbrio. A água do plano acima das nuvens é sinônimo de fertilidade, contrário ao hua-hohopadé dsa onde a seca indica infertilidade. Tanto a fertilidade quanto a infertilidade interferem diretamente no nami, o plano no qual se vive.

Há, também, uma oposição entre o memé tsuení e o namibudi. No primeiro, a carne é ruim, não sendo propícia para a caça. O segundo indica a carne boa para a caça, refletindo a relação mais íntima dos Madija que vivem no nami em interface direta com seu duplo, o namibudi. A ligação entre esses dois mundos marca a relação de sobrevivência dos Madija, pois é para o namibudi que vão as almas dos animais. Estas retornam materializadas no corpo de animais através da mediação do dsoppineje, quando a aldeia precisa de alimento. Por conseguinte, aparecem pacas, cutias, porcosdo-mato, veados e outros bani bons para comer.

Neste ponto, requer atenção o fato de que a carne boa está relacionada à saúde, enquanto a carne ruim se refere à impureza. A carne boa é consumida porque é sadia e, portanto, indica a cura, já que o dsoppineje não vai buscá-la em algum espírito de 
Disponível em: www.revistafenix.pro.br

animal que pertence ao memé tsuení (onde se localizam os animais impuros). Consequentemente, os espíritos de animais vindos do namibudi são considerados limpos e invocados para purificação. É a carne desses animais que alimenta e mantém os Madija saudáveis.

Resulta dessa forma de entendimento, a importância atribuída ao dsoppineje em estabelecer uma relação mais íntima com o namibudi, pois é nele que se formarão alianças com os espíritos em proveito de alimentação e saúde. Desse modo, como as almas ou espíritos sobem limpos para serem comidos, igualmente são responsáveis por eliminar a sujeira e realizar a cura.

\section{A IMPORTÂNCIA DO TEMPO DOS AVÓS}

Em sua forma particular de se relacionar com o tempo, os Madija aplicam uma divisão consubstanciada em histórias antigas e histórias recentes. As primeiras remetem ao tempo dos avós primordiais da criação, se referem aos heróis mitológicos, seres míticos, lugares e elementos sagrados.

As narrativas de origem são chamadas de "história antiga" ou "história de nossa gente". O ato de narrar ou contar é uma forma de atualizarem as histórias primordiais e se autoafirmarem no mundo. Na concepção dos Madija, o mundo foi criado por dois heróis mitológicos: Quira e Tamaco. O primeiro, mais velho, passava o tempo todo ensinando ao mais novo as formas de utilizar seus poderes. Nestes termos, cabe apontar que essa relação de transmissão de conhecimentos é igualmente observada na atividade de pajelança. Os heróis mitológicos foram os responsáveis pela criação de plantas, espécies de animais e outras raças de gentes (indígenas ou não). Os elementos que compõem o plano no qual se vive foram resultado da criação primordial e se relacionam com a contínua construção de suas vidas.

Outra particularidade a ser destacada é a de que na narrativa mítica de criação do mundo Madija não há uma ordem cronológica linear e inalterável. No rastro desse entendimento, são percebidas várias fases do tempo mítico passíveis de rupturas, marcadas por catástrofes, destruições e tragédias de um lado, e de renovação, revitalização e reconstituição de outro. Em vista disso, são configuradas as mudanças entre os conjuntos de histórias do "tempo mais antigo dos avós". 
Disponível em: www.revistafenix.pro.br

As destruições podem ocorrer através do fogo, da água e de outros elementos da natureza. Como resultado, é possível pensar em vários momentos do tempo antigo para também apreendê-los como historicidade. Entre os Madija isso ficou claro no relato da criação através da destruição da aldeia mítica por Massosso ${ }^{12}$, ocasião em que Quira e Tamaco reconstruíram a comunidade primordial, onde moravam os primeiros Madija.

Cada uma dessas destruições representa um rompimento com um tempo e o início de uma nova idade. Quando Quira e Tamaco exterminaram seus avós onça ocorreu renovação e revitalização demarcando uma passagem mítica. Há outras rupturas pontuadas por narrativas descontínuas sobre o tempo dos avós, as histórias mais antigas, nas quais se encontra a essência da vida.

\section{MUNDOS, TEMPOS E HISTÓRIAS}

As histórias dos tempos dos avós da criação são chamadas de Ididenicca Ima. Conforme ressaltado no tópico precedente, elas se reportam à origem dos Madija, sendo relevantes para a memória e identidade desse povo.

A essas proposições, Cerqueira (2015), que realizou estudos na Terra Indígena Alto Rio Purus, esclarece que a forma pela qual são tratados os ancestrais desse povo se desdobram em:

[...] temporalidade através da repetição de determinados aspectos descritos tanto para um passado longínquo - reconhecido como tempo fora do tempo - o tempo mítico dos heróis demiurgos - como para um passado anterior a chegada dos brancos - como também para um passado recente. (CERQUEIRA, 2015, p.88)

No aprofundamento de suas análises, o autor citado identifica três tempos no Alto Rio Purus: tempo mítico dos ancestrais, tempo anterior ao contato com cariah e tempo recente a partir do contato. Esses tempos configuram uma amálgama e se manifestam em narrativas (CERQUEIRA, 2015).

Ressalta-se, contudo, que entrevistas efetuadas no Alto Rio Envira conduziram a uma conclusão oposta, pois observou-se que os tempos estão dentro de tempos, e não fora deles como apontou o autor em comento. Como visto, os Madija diferenciam o

12 Entidade mítica dotada de poder que destruiu a aldeia do povo Madija como ato de vingança pela morte de seu filho. 
Disponível em: www.revistafenix.pro.br

passado mais antigo que faz parte dos tempos primordiais, de criação, dos avós ancestrais. Todavia, pelo que se pode perceber o tempo não está fora do tempo, mas dentro de outros tempos, sendo manifestado através de representações.

Com essa característica ressaltada, Altmann (2000) informa que esse povo faz a sua divisão em apenas dois tempos, e não três como mencionado por Cerqueira (2015). Para esta autora, a convenção temporal é expressa por meio de duas eras que correspondem ao tempo dos antigos e ao tempo atual. Esclarecendo seu posicionamento, cita que a palavra maittaccadsama representa algo muito antigo. Ela faz parte, também, do maittaccadsamappa, do antigamente, do começo de tudo, onde se expressa o Ididenicca Ima (FUNAI, 1985). Estes tempos se diferem do hipadana, correspondente ao hoje, atualmente, agora.

Diante dessas explanações, Balestra (2013) argumenta que esse último tempo ainda está em construção. Nas premissas observadas pela autora, a mudança dos tempos antigos se dá pela ruptura entre a passagem do "brabo" do interior da floresta para o "manso" da beira de rio, momento no qual foram incorporados ao sistema extrativista da borracha.

E aqui se adota posicionamento distinto, pois se pressupõe que o tempo mais recente não se deu com a ruptura do contato com os cariús por conta do sistema extrativista da borracha. Mesmo com a constatação de que o contato alterou relações socioculturais e promoveu a desagregação dos grupos, infere-se que não deve ser pensado como ponto de cisão ou ruptura entre os tempos. Reforçando essa ideia, as entrevistas realizadas na comunidade Igarapé do Anjo (Terra Indígena Kulina do Rio Envira) apontam que o tempo recente é aquele no qual a memória consegue alcançar e que antecede o contato com os cariús, quando os vovôs e vovós de velhos, ainda vivos, moravam nas odsa beje e tinham outro modo de vida. Portanto, o hipadama não deve ser entendido arbitrariamente como momento de passagem de "brabo" a "manso", ou de moradores do interior da floresta para a beira de rios, mas como referencial de alcance da memória coletiva.

A essas proposições, acrescente-se que o entrelaçamento entre as histórias dos tempos antigos e as mais recentes compõem o Madijadenicca Ima ou "histórias de nossa gente". Neste sentido, os tempos se mesclam e se encontram em diversos momentos da vida desse povo. Eles são revividos por intermédio das narrativas que se revelam como um dos principais suportes da memória e elos dos tempos. 
Tomando como referência essa afirmativa, postula-se que tudo é história, todos os tempos estão interligados e não podem ser observados de forma linear e cartesiana como privativo de um ou outro tempo. Sendo assim, os tempos se inscrevem uns nos outros e reaparecem em situações específicas por meio de representações simbólicas.

Além das histórias do tempo antigo (Ididenicca Ima e maittaccadsama), existem aquelas mais atuais nas quais estão incluídos o contato com frentes pioneiras e outros eventos contemporâneos. Nessa diretriz, entabulam uma série de histórias descontínuas que incluem, por exemplo, "amansamento" de índios, exploração dos marreteiros, criação da terra Madija, dívidas nos comércios da cidade com cartão Bolsa Família, dentre outras.

Cite-se, à guisa de exemplificação, narrativas que se reportam ao início do século XX, período no qual os ancestrais viviam nas odsa beje (malocas grandes) sob a liderança de Josama. Quando este personagem ainda era tamine (liderança política) no igarapé Cumaru, afluente do Jaminauá, tributário do rio Envira, foram contatados por cariús $^{13}$ para serem "amansados" pelos seringueiros a mando de seringalistas, que diziam: “- hei índio, vem pra cá! - não vem flechar, eu sou bom! vamos fazer assim, eu dou roupa pra você e pra todo mundo. Aí vovô vem e ele: - tá aqui roupa pra usar! usa roupa, aí deu calça comprida e camisa" (Bedi Madija, 18 dez. 2010).

As histórias dos avós acompanham um outro tempo histórico no qual eles foram atraídos, escravizados e subordinados ao trabalho, sendo obrigados a executar diversas tarefas e a mudar seus locais de moradia do interior da floresta para a margem do rio Envira por causa do seringal Califórnia.

Neste contexto de contato, passaram a consumir produtos industrializados como: farinha, rapadura, tabaco, roupa, terçado, faca (Bino Madija, 20 dez. 2010). Essas mercadorias eram trocadas por produtos dos roçados e da floresta. Tais permutas foram incorporadas ao manaco, sistema de trocas desenvolvido na fase anterior ao contato com os cariús e no qual eram intercambiados produtos entre as comunidades Madija e com comunidades pertencentes a outros povos. Revele-se que as trocas se tornaram uma estratégia de dominação do seringalista para com esses índios, proporcionando sua inserção no sistema capitalista e crescente dependência dos produtos industrializados.

13 Esclarece-se que cariú ou cariha são termos mais recentes. Na fase anterior ao contato, o vocábulo utilizado para não-índios era maribuna. 
Como desconheciam o papel-moeda, faziam trocas para pagar o patrão e passavam a se endividar com os seringalistas ao adquirir produtos industrializados do barracão no seringal Califórnia (Alto Rio Envira) configurando um sistema de escravidão, posto que não podiam abandonar o seringal sem antes saldar seus débitos.

Em cima do União, papai fazeu roçado. Aí em cima do roçado planta milho, planta cana, planta bananal, planta macaxeira, morava aí. Ele caçava, matava bado (animal), com espingarda não, só com flecha mesmo. Meu pai flechava veado, porquinho, macaco preto também, capelão, jomo (macaco). Cariú bom, nós comia leite, sardinha, compra açúcar, sal e meu pai paga com dsanecoa (jabuti). Com dsanecoa compra sal, tabaco, aí compra roupa, puhi (rede), mosqueteiro. Madija fazia manaco para pagar patrão (JOÃO CUMARU, 22 dez. 2010).

Narrativas sobre dependência transparecem ainda nos relatos de trabalhos executados na Fazenda Califórnia na década de 1970: “- ô Manoelzinho, Cazuza, Peres, Binô, vai trabalhar lá. Domingo vai ter muita mercadoria, vai lá, vocês compra mercadoria lá! Aí nós trabalhamos lá, ficamos escravos, compramos mercadoria, compramos roupa, maleta, panela. Aí nós subimos” (Melk Madija, 20 dez. 2010).

Na Fazenda Califórnia exerciam atividades de mateiro, caçadores, pescadores e cultivadores de roçado para abastecer a sede da unidade produtiva. O manaco permitia troca por chumbo para arma de fogo, enlatados, sal, açúcar, tecidos, espelhos e outras quinquilharias que eram ofertadas para as famílias indígenas. ${ }^{14}$

As histórias dos avós acompanham também a luta pela posse da terra no final da década de 1970 e a implantação da primeira escola pelo Conselho Indigenista Missionário (CIMI) que encaminhou, inicialmente, o italiano Giovanni e, posteriormente, Abel Kanaú Silva, indigenista e historiador, para realizar experiências em educação bilíngue. Este último assessorou a Fundação Nacional do Índio (FUNAI) na demarcação da Terra Indígena Kulina do Rio Envira.

O tempo dos avós é rememorado em histórias que manifestam a percepção de doenças que não faziam parte da cultura desse povo e que, portanto, não era possível sua cura pela medicina tradicional. Comungando com essa premissa, está o relato de que: “[...] pegava doença do branco. Aí tinha pneumonia, malária. Brabo num chegou a

14 Vale ressaltar que o processo de "amansamento" produziu laços de subordinação ao patrão que era chamado de "papai" ou "mamãe". A mesma designação era aplicada para determinadas lideranças políticas de outros povos indígenas que participaram de "correrias" contra os Madija. Nesse aspecto, "papai" ou "mamãe" configura uma representação linguística e se refere, também, ao "amansamento". 
agüentar não. Não tem remédio. Antigamente não comprava remédio, não tinha remédio. Morreu muito índio" (BEDI MADIJA, 18 dez. 2010).

Deve-se salientar, nesse âmbito, a existência de uma série de histórias cruzadas que fazem parte da linha ou malha de vida desse povo. É mister destacar que os termos "linha" e "malha" foram problematizados por Tim Ingold. De acordo com este autor, cada pessoa tem uma linha contínua de vida que se intercruza a outras linhas formando uma "grande teia" na qual as pessoas estão abertas, sendo a vida um nascimento contínuo. Essa linha corresponde a uma trilha que acompanha o indivíduo durante a vida e faz inúmeras associações ao ambiente, assim como fios que, juntos, correspondem à textura do mundo da vida. Esta textura nada mais é do que o campo relacional. Nesse caminho, seres, mundos e tempos constituem parte deste entrelaçamento (INGOLD, 2015).

A relação entre as pessoas não é meramente um encontro, mas um intercruzamento entre suas experiências de vida. Estas, por exemplo, podem ser histórias cruzadas entre as pessoas que não vivem passivamente no mundo, mas são o próprio mundo e as linhas o movimento. Logo, não são os seres que estão em movimento e sim as linhas das quais fazem parte. Sendo assim, as pessoas quando se movem tornam-se linhas; os seres não existem em determinados lugares, eles ocorrem ao longo de caminhos e, nessa lógica, pessoas são reconhecidas pelas trilhas que deixam atrás de si.

Aprofundando suas considerações, o autor em comento afirma que tudo que existe em todos os mundos de cosmologias diversas devem ser respeitado porque se movimenta. Por conseguinte, as visões cosmológicas necessitam de valorização, posto que incluem particularidades de como grupos, comunidades e sociedades compreendem o movimento a partir das diversas existências humanas e não humanas. Nesse caso, os mundos estão ligados em campos indivisíveis que são integrados ao longo das linhas de vida entrelaçadas das pessoas. Tudo se mistura na percepção de mundo, que passa a ter nascimento contínuo (INGOLD, 2015).

Todo este conjunto de histórias é reatualizado através de performances que são repassadas às gerações por meio de narrativas e ações se constituindo, dessa forma, em estratégias de reprodução sociocultural. Portanto, as narrativas dos tempos dos avós que eram contadas nas odsa beje dos ancestrais e as de momentos mais recentes nas casas de família e nos pátios das comunidades são formas de reviver o tempo antigo por meio da 
Disponível em: www.revistafenix.pro.br

linguagem. Em contrapartida, o tempo dos avós é recontado através de brincadeiras, festas lúdicas e cerimônias sagradas, conforme está explicitado na sequência.

\section{DSOPPINEJE COMO CONFLUENCIA ENTRE TEMPOS, MUNDOS E HISTÓRIAS}

Aborda-se, em primeiro lugar, que o dsoppineje deve ser entendido na ótica de um sistema relacionado ao contexto coletivo das aldeias indígenas no Alto Rio Envira. A par disso, ele manifesta a visão de mundo do tempo antigo por meio de seus aspectos simbólicos. Realizado esse esclarecimento, examina-se tal sistema mostrando sua articulação a outras áreas do conhecimento.

$\mathrm{Na}$ medicina dsoppineje não são delimitadas fronteiras entre homem $\mathrm{e}$ natureza, mas uma integração que permeia todos os seus aspectos. Neste mundo (nami), os Madija vivem da relação doença/saúde e desequilíbrio/equilíbrio. Dsoppineje nada mais é do que um termo sinônimo para o vocábulo saúde. Como corolário, a saúde que permeia a vida desse povo é encontrada em caças sadias (bani), bijini (rios e igarapés), coridsa (lagos), aba (peixe) de couros e escamas, plantas, ikorimes (almas) e em diversos outros aspectos, como a pajelança.

Tradicionalmente o pajé é o especialista local no tratamento de doenças, sendo chamado também de dsoppineje. Não obstante, a terminologia é utilizada para designar outros profissionais da medicina, como médicos, enfermeiros, agentes de saúde e de saneamento.

$\mathrm{Na}$ concepção dos moradores da comunidade Igarapé do Anjo, antigamente todo homem era dsoppineje. Este especialista tem características dos avós onça, Massosso (ser sagrado do tempo primordial) e de ikorimes, as almas de animais ou antepassados pajés que continuaram seguindo os passos mitológicos de "voar para longe", seguindo a odisseia dos heróis, viajando a outros lugares, assim como fizeram os irmãos Quira e Tamaco, criadores das coisas que existem neste mundo. Em outros planos, dialogam com seres e com eles aprendem.

O dsoppineje, em sua atividade, "voa para longe" transitando por mundos, negociando a cura com as almas, a saúde daqueles que estão doentes. A cura adquire uma performance ritual, na qual esse especialista do êxtase é a peça fundamental na mediação dos mundos e na reativação dos símbolos primordiais da criação. A sua 
performance é um dos atos mais espetaculares desta cultura para manifestar o Ididenicca Ima.

Na cura, o dsoppineje se metamorfoseia no espírito e se manifesta por meio de danças, gestos e sons. Geralmente retorna representando formas de animais e, mais raramente, incorporando pajés falecidos. Tais espíritos vivem no mundo abaixo da terra (namibudi). É lá que o dsoppineje vai negociar a cura com o espírito. Então, assume o seu lugar para que ele venha ao nami e com seus poderes proporcione o equilíbrio físico e espiritual da pessoa e da própria comunidade.

Prevalece a crença segundo a qual os ikorime atravessam buracos sagrados localizados entre caminhos que ligam o pátio das comunidades aos roçados para alimentar os Madija. Diante do exposto, percebe-se que a cura representa uma espécie de aliança entre o dsoppineje e os ikorimes. Esses buracos por onde ocorre a troca entre as almas de animais ou pajés antigos com a do dsoppineje são denominados dsacatana.

O sina, tabaco misturado à cascas de árvores, é torrado e se transforma em pó escuro para ser inalado. Tal elemento é apontado como o responsável pela condução do pajé a outros mundos, assim como para trazer os espíritos ao mundo humano através de manifestações no corpo com vistas à extração do dori. ${ }^{15}$

Dos inúmeros atributos e significados atribuídos ao dori, pode-se destacar o relacionado ao feitiço. Ele remete à narrativa da história antiga na qual os dois heróis mitológicos mataram o filho de Massosso, daí originando a tragédia desse povo personificada no assassinato do filho desta entidade da mata e na destruição da aldeia mítica. Outras tragédias se sucederam, provocando destruição e consequências irreversíveis, do que constituem exemplos as "correrias".

O dori é uma substância que permeia todo o corpo do dsoppineje. Pode ser materializado no formato de pedra, fragmento de madeira, unha de tatu ou de outro animal, permitindo-se que seja introduzido na região do abdômen. Neste particular, chama-se a atenção para a capacidade do dori em tirar rapidamente a vida de uma pessoa.

Em resumo a essas considerações, trata-se de substância ambígua que se concretiza e cresce no corpo do dsoppineje. Na história primordial, Massosso foi

15 Destaca-se que além do sina, também utilizam o rami (ayahuasca). Estes servem como ferramenta para que os aprendizes e os pajés possam entrar em contato com o mundo dos espíritos. São considerados ainda como fonte de aprendizagem, além de serem empregados para reviver os tempos e realizar previsões. 
transformada no dori por Quira e Tamaco, mas a sua cólera se materializou no dori e, por isso, o dsoppineje pode tanto curar quanto matar. ${ }^{16}$

Na verdade, Tamaco e Quira domesticaram o dori. Seguindo os passos dos criadores, os dsoppineje necessitam contê-lo a fim de que possa "voar para longe". Consoante com esse objetivo, o processo de iniciação xamânica requer treinamento no qual os jovens são iniciados por um homem mais velho. É nessa transmissão de poder que o iniciando aprende a dominar a substância como nos tempos primordiais.

A adolescência constitui o período reputado como ideal para realizar a transmissão de poder, embora haja relatos de aprendizes adultos e de raríssimos casos de mulheres após a menopausa. No processo de aprendizado são repassados aos cahuaniji dois tipos de dori: o koronaua e o noma. O koronaua ensina o caminho do bom canto que, assim como a dança, são as formas poderosas de manifestação dos dsoppineje Madija diante dos humanos e dos ikorimes. O noma auxilia o jovem durante o processo da aprendizagem xamânica. Esse aprendizado entre adolescentes e adultos pode levar aproximadamente um ano, período no qual os iniciandos são submetidos a restrições que incluem: dieta alimentar, abstinência sexual e acesso a jogos, festas e brincadeiras.

De fundamental importância é a ideia de esses jovens aprenderão com os mais velhos as formas e os caminhos que poderão transportá-los a outros mundos quando desejarem, especialmente ao namibudi, e a fazer o uso acertado do dori, pois o emprego inadequado pode colocar em perigo indivíduos e toda a comunidade.

Os saberes da cura são transmitidos através da oralidade e os mais velhos, que gozam de boa reputação na comunidade, se responsabilizam pelos ensinamentos aos mais novos, reforçando uma prática de memória que vem ocorrendo desde os tempos das odsa beje. Logo, contar história antiga é uma forma de repassar o conhecimento dos avós, daqueles que viveram nos tempos antigos. Os Madija nutrem grande respeito pelas narrativas, fundamentais na ligação desse povo aos seus ancestrais e aos seres não humanos que estão em outros mundos e transitam sobre aquele no qual vivem. Consideram que ensinar aos mais novos é uma arte que se configurou no tempo primordial quando Quira instruía e transmitia para Tamaco os seus poderes mágicos.

16 Sublinha-se que existem outras narrativas associando o ato de traição aos avós onça que pretendiam comer os heróis primordiais. Descoberto o intento, foram mortos por Quira e Tamaco. A onça (dsumahe) é um ser traiçoeiro, mas é respeitada por esse povo, que a considera poderosa, sábia e ancestral antigo, reportando-a ao tempo no qual os Madija se metamorfoseavam entre gente e bicho. 
Deve-se atentar que existem outras formas de repassar saberes. Estas estão presentes nos afazeres das comunidades e incluem atos como cozinhar, caçar, pescar, preparar e tirar o roçado, andar na mata, fazer medicina ou ainda aprender a extrair o dori do corpo de alguém. Nesse contexto, toda lógica que envolve o repasse de saberes é chamada de papehuahua. Isso posto, o processo de iniciação de um cahuaniji para se tornar dsoppineje é, também, papehuahua, posto que o aproxima da ancestralidade através do treinamento para lidar com as doenças que pertencem ao quadro simbólico e cultural desse povo.

Em contraposição, existem as doenças que são "de fora" e foram adquiridas por meio do contato com os cariús. Essas enfermidades incluem a gripe, sarampo, catapora, tuberculose, coqueluche, gonorreia, hepatite, pneumonia, vaginite, catapora, malária e crista de galo. Nesse caso, consideram que toda doença exógena pode ser tratada por dsoppineje da cidade (médicos, enfermeiros e outros especialistas da área da saúde).

As doenças Madija incluem o epetuka'i e o dori e há intervenção direta do conjunto de dsoppineje das comunidades. O epetuka'i é uma enfermidade exclusiva de bebês. Ela é decorrente da quebra de tabus alimentares, problemas familiares como discussão entre homem e mulher, relacionamentos extraconjugais e fracasso de um genro na obtenção de alimentos para o pai da esposa. O dori, por seu turno, é considerado como uma doença. Ele afeta adultos, mas raramente crianças pequenas e bebês. Os adultos contraem o dori por hostilidade de um dsoppineje. No caso de crianças ficarem doentes por dori, consideram que inveja, raiva e outros fatores que deveriam recair sobre seus pais podem tê-las atingido.

No ritual de cura, seja para epetuka'i ou para dori, o dsoppineje vai buscar as almas investidas de poder para curar no namibudi. Dessa maneira, ele pode voltar transformado no jidsama tokorime, isto é, um queixada, que para os membros do grupo espelha sua vida em sociedade. O queixada anda em bandos e é para o seu corpo que é encaminhada a carne dos Madija quando morrem. Esses tokorimes representam o lado feminino e delicado desse povo, um contraponto ao jidsama tokorime, dsumahe tokorime ou espírito da onça, que manifesta justamente o oposto, ou seja, o lado agressivo, solitário e masculino, referindo-se ao caçador predador e indomável.

A cura é executada geralmente durante o período noturno para que o espírito possa obter uma visão melhorada do objeto introduzido no corpo do enfermo, pois a luz 
do dia pode atrapalhar a visão do feitiço. Ao passo que a alma não consegue extraí-lo, ocorre seu retorno para a mata permitindo a vinda de outra e assim sucessivamente, marcando uma sequência de buscas e tentativas cuja duração pode variar de horas a dias na qual se tenta, através de sucção no local afetado, extrair o dori. De acordo com a cor do feitiço, o dsoppineje poderá externar o grau de gravidade da doença e se o paciente viverá ou morrerá (POLLOCK, 1992).

Quando o dori é extraído, o espírito ou alma salta e dança aceleradamente mostrando-o aos demais integrantes da aldeia. Festejam e são legitimados pelos que assistem à cura. Após a extração do dori, o paciente deve tomar um banho com água fria para se desprender das marcas dos resíduos impuros que possam estar contidos em seu corpo. Enquanto esse ritual se desenrola, é servido coidsa (bebida fermentada de mandioca) para o ikorime que se encontra no corpo do dsoppineje. Essa bebida pode ser apresentada, ainda, por meio de cânticos entoados principalmente pelas mulheres.

No contexto cultural em questão, qualquer homem adulto pode ter essa habilidade, com a ressalva da desconfiança em relação àqueles que são mais afastados da comunidade. Quando o dsoppineje causa algum mal jogando o dori, não demora para ser acusado por outro especialista. Em consequência, cura e acusação caminham juntas, pois ao passo que ocorre a recuperação física e espiritual torna-se sua a responsabilidade de indicar a origem do feitiço e quem cometeu o ato. ${ }^{17}$ Portanto, a acusação fornece a este ator grande prestígio perante a comunidade ao passo que a informação pública pode provocar cisões no âmbito das comunidades.

Para celebrar a cura é realizado um tokorime (festa das almas). Nessa celebração os ikorime são chamados para dançar e realizar manaco_(troca e reciprocidade). Além do tokorime, o manaco é encontrado em festas, jogos, danças, pinturas, relações familiares e atividades cotidianas. Contudo, extrapola tudo isso posto que até mesmo pequenos gestos como o sorriso podem se enquadrar ao conceito.

O tokorime é efetuado em momentos especiais, notadamente após a cura de algum enfermo. Parte da estrutura desta festa é semelhante ao ritual de cura, ocasião em que as almas são chamadas para equilibrar a vida. A diferença é que no tokorime os ikorime são convocados para celebrar a vitória da saúde sobre a doença e do bem contra o mal.

17 É digno de nota mencionar que o dsoppineje pode jogar o feitiço, embora sejam reportados casos de solicitação destes aos ikorimes (almas) para que lancem o dori a terceiros. 


\section{CONSIDERAÇÕES FINAIS}

Na sociedade Madija tempos, mundos e histórias estão fortemente associados. Nessa lógica própria, o Ididenicca Ima e maittaccadsama estão articulados às histórias recentes e que continuam em construção. As histórias dos tempos antigos, traduzidas por meio das narrativas orais, são fundamentais para a memória e identidade desse povo.

O tempo recente se arquiteta em consonância com a vivência do tempo dos avós, sendo especialmente marcada em suas representações simbólicas do hipadana, que é alimentado por histórias do outro tempo. O tempo recente é construído em momentos cotidianos, lúdicos e ritualísticos, a exemplo do dsoppineje, o complexo sistema de saúde que vai além da percepção sobre pajelança, embora esteja alicerçado nas relações de construção de poder e cura.

O dsoppineje, no sentido coletivo e do seu principal agente (pajé), constitui uma forma de confluência entre tempos, mundos e histórias. Para além isso, é um modo de afirmação, existência e fortalecimento desse povo no plano em que vivem. Ele é vital para o equilíbrio do nami, visto que acreditam que no dia em que não houver mais dsoppineje sobre a terra o planeta e todas as coisas que nele existem serão destruídas por um grande dilúvio marcando, com isso, o fim da existência de todos. Nessa perspectiva, não haverá mais tempos, mundos e histórias.

\section{REFERÊNCIAS BIBLIOGRÁFICAS}

ALMEIDA, Maria Celestino de. Os índios na história do Brasil. Rio de Janeiro: FGV, 2010.

ALTMANN, Lori. Madija: um povo entre a floresta e o rio - trilhas de produção simbólica Kulina. 1994. Dissertação (Mestrado em Ciências da Religião) - Instituto Metodista de Ensino Superior, São Bernardo do Campo, 1994.

Maittaccadsama: categorias de espaço e tempo como referenciais para a identidade Kulina (Madija). 2000. Dissertação (Mestrado em Antropologia Social) Universidade Federal do Rio Grande do Sul, Porto Alegre, 2000. 
ARAÚJO, Wladimyr Sena. Breve histórico de ocupação territorial do Acre. In: ACRE. Secretaria de Estado de Ciência, Tecnologia e Meio Ambiente. Zoneamento ecológicoeconômico do estado do Acre. Rio Branco: SECTMA, 2000. p. 151-158. Relatório do etnozoneamento da terra indígena Kulina do rio Envira. Rio Branco: SEMA, 2012.

Richard Spruce e Alfred Russel Wallace: naturalistas do século XIX e o encontro com caapi. Jamaxi, Rio Branco, v. 2, n. 2, p. 141-158, 2018. Disponível em: $\langle$ https://periodicos.ufac.br/index.php/jamaxi/article/view/2267>. Acesso em: $24 \mathrm{fev}$. 2020.

BALESTRA, Aline Alcarde. Tempos mansos: história, socialidade e transformação no Juruá-Purus indígena. 2013. Dissertação (Mestrado em Antropologia Social) Departamento de Antropologia, Universidade de Brasília, Brasília, 2013. Disponível em:

<https://repositorio.unb.br/bitstream/10482/13210/1/2013_AlineAlcardeBalestra.pdf $>$.

Acesso em: 28 fev. 2020.

CERQUEIRA, Felipe Agostini. Os mundos, os corpos e os objetos: o xamanismo como troca entre os Madiha e outros seres. 2015. Tese (Doutorado em Sociologia e Antropologia) - Instituto de Filosofia e Ciências Sociais, Universidade Federal do Rio de Janeiro, Rio de Janeiro, 2015.

FUNAI. Área indígena Culina do Médio Jurua e área indígena Cacau do Itarauacá: proposta para delimitação. Rio Branco: Funai, 1985. Relatório datilografado. Disponível em: <https://acervo.socioambiental.org/sites/default/files/documents/KVD00020.pdf>. Acesso em: 2 mar. 2020.

IGLÉSIAS, Marcelo Manuel Piedrafita. Os Kaxinawá de Felizardo: correrias, trabalho e civilização no Alto Juruá. 2008. Tese (Doutorado em Antropologia Social) Programa de Pós-Graduação em Antropologia Social, Museu Nacional, Universidade Federal do Rio de Janeiro, 2008. Disponível em: 〈http://www.dominiopublico.gov.br/download/texto/cp064338.pdf $>$. Acesso em: 1 mar. 2020.

INGOLD, Tim. Estar vivo: ensaio sobre movimento, conhecimento e descrição. Petrópolis: Vozes, 2015.

POLLOCK, Donald K. Kulina shamanism: gender, power and knowledge. In: E. Jean Langdon and G. Baer (Eds.). Portals of power: shamanism in South America. Albuquerque: University of New Mexico Press, 1992. p. 25-40.

TASTEVIN, Constantin. Informações sobre Kulina e Kaxinawá no Tarauacá e Acuraua. [S.1.], 1908-1914. Manuscrito. Biblioteca Nacional (Rio de Janeiro).

. Le "Riozinho da Liberdade". La Geographie, t. 489, n. 3-4, p. 205-215, 1928.

TAUSSIG, Michael. Xamanismo, colonialismo e o homem selvagem: um estudo sobre o terror e a cura. São Paulo: Paz e Terra, 1993.

VIVEIROS DE CASTRO, Eduardo. Os Culina do Alto Rio Purus. Rio de Janeiro: Museu Nacional, 1978. Relatório datilografado.

\section{ENTREVISTAS}

Bedi Madija. Entrevista concedida a Wladimyr Sena Araújo. Aldeia Igarapé do Anjo, Feijó-AC, 18 dez. 2010.

Bino Madija. Entrevista concedida a Wladimyr Sena Araújo. Aldeia Igarapé do Anjo, Feijó-AC, 20 dez. 2010. 
Disponível em: www.revistafenix.pro.br

João Cumaru. Entrevista concedida a Wladimyr Sena Araújo. Aldeia Igarapé do Anjo, Feijó-AC, 22 dez. 2010.

Melk Madija. Entrevista concedida a Wladimyr Sena Araújo. Aldeia Igarapé do Anjo, Feijó-AC, 20 dez. 2010. 